\title{
Correction of Chronic Hyperglycemia with Vanadate, But Not with Phlorizin, Normalizes In Vivo Glycogen Repletion and In Vitro Glycogen Synthase Activity in Diabetic Skeletal Muscle
}

\author{
Luciano Rossetti and Maren R. Laughlin \\ Departments of Medicine, Yale University School of Medicine, Yale University, New Haven, Connecticut 06510; \\ and University of Texas Health Science Center, San Antonio, Texas 78284
}

\begin{abstract}
Vanadate has insulin-like activity in vitro and in vivo. To characterize the in vivo mechanism of action of vanadate, we examined meal tolerance, insulin-mediated glucose disposal, in vivo liver and muscle glycogen synthesis, and in vitro glycogen synthase activity in $90 \%$ partially pancreatectomized rats. Four groups were studied: group I, sham-operated controls; group II, diabetic rats; group III, diabetic rats treated with vanadate; and group IV, diabetic rats treated with phlorizin. Insulin sensitivity, assessed with the euglycemic hyperinsulinemic clamp technique in awake, unstressed rats, was reduced by $\sim 28 \%$ in diabetic rats. Both vanadate and phlorizin treatment completely normalized meal tolerance and insulin-mediated glucose disposal. Muscle glycogen synthesis was reduced by $\sim 80 \%$ in diabetic rats $(P<0.01)$ and was completely restored to normal by vanadate, but not by phlorizin treatment. Glycogen synthase activity was reduced in skeletal muscle of diabetic rats $(P<0.05)$ compared with controls and was increased to supranormal levels by vanadate treatment $(P<0.01)$. Phlorizin therapy did not reverse the defect in muscle glycogen synthase.

These results suggest that $(a)$ the defect in muscle glycogen synthesis is the major determinant of insulin resistance in diabetic rats; $(b)$ both vanadate and phlorizin treatment normalize meal tolerance and insulin sensitivity in diabetic rats; (c) vanadate treatment specifically reverses the defect in muscle glycogen synthesis in diabetic rats. This effect cannot be attributed to the correction of hyperglycemia because phlorizin therapy had no direct influence on the glycogenic pathway.
\end{abstract}

\section{Introduction}

The insulin-mimetic properties of vanadate were described in isolated adipocytes by Dubyak and Kleinzeller (1) and Schechter and Karlish (2) in 1980. Since then, numerous reports have elucidated the intracellular mechanism(s) whereby vanadate mimics insulin action in adipocytes (1-6), skeletal muscle $(7,8)$, hepatocytes $(9-11)$, and other cell types $(12,13)$.

Heyliger et al. (14) first proposed the in vivo insulin-like activity of the element, because its oral administration normal-

Address reprint requests to Dr. Luciano Rossetti, Diabetes Division, Department of Medicine, University of Texas Health Science Center, 7703 Floyd Curl Drive, San Antonio, TX 78284.

Received for publication 15 November 1988 and in revised form 14 April 1989.

J. Clin. Invest.

(C) The American Society for Clinical Investigation, Inc.

0021-9738/89/09/0892/08 $\$ 2.00$

Volume 84, September 1989, 892-899 ized the plasma glucose concentration in streptozocin-diabetic rats, without significant increase in the plasma insulin concentration. Recently, Meyerovitch et al. (15) further characterized the mode of action of vanadate in diabetic rats by suggesting that the improvement in the basal rates of hexose uptake in liver and skeletal muscle was primarily responsible for the reduction in circulating plasma glucose level. However, the relative contribution of each of the various intracellular actions of vanadate $(1-13)$ to its in vivo blood glucose lowering effect has yet to be delineated.

We have recently demonstrated that the correction of chronic hyperglycemia with phlorizin $(16,17)$, an inhibitor of renal tubular glucose reabsorption, completely reverses the defect in insulin-mediated glucose disposal, which characterizes the partially pancreatectomized diabetic rats. In this study, we use vanadate and phlorizin as tools to further delineate the intracellular defect(s) in insulin-mediated glucose metabolism in an animal model of non-insulin-dependent diabetes mellitus.

The effect of prolonged vanadate therapy on plasma glucose and insulin concentrations, whole body insulin-mediated glucose uptake, in vivo muscle glycogenic rates, and in vitro glycogen synthase activity is examined in partially pancreatectomized rats. To dissect out the beneficial effects of the correction of chronic hyperglycemia $(16,17)$ from the specific in vivo action(s) of vanadate, we compare diabetic rats treated with phlorizin, which corrects hyperglycemia but is devoid of any known insulin-mimetic properties, or with vanadate.

Our results indicate that the glycogenic pathway in skeletal muscle is severely impaired in diabetic rats and is the major site of the in vivo effects of vanadate on glucose metabolism.

\section{Methods}

Animals. Four groups of male Sprague-Dawley rats (Charles River Breeding Laboratories, Wilmington, MA) were studied: group I, sham-operated controls $(n=9)$; group II, partially pancreatectomized rats $(n=9)$; group III, partially pancreatectomized rats treated with vanadate $(n=9)$; group IV, partially pancreatectomized rats treated with phlorizin $(n=7)$. When 3-4 wk old, all rats $(80-100 \mathrm{~g})$ were anesthetized with phenobarbital $(50 \mathrm{mg} / \mathrm{kg}$ body wt i.p.) and in groups II, III, and IV $90 \%$ of their pancreas was removed according to the technique of Foglia (18), as modified by Bonner-Weir et al. (19). Group I underwent a sham pancreatectomy in which the pancreas was disengaged from the mesentery and gently rubbed between the fingers. Sodium metavanadate $(0.2 \mathrm{mg} / \mathrm{ml}$ in drinking water) or phlorizin $(0.4$ $\mathrm{g} / \mathrm{kg}$ body weight s.c., prepared as a $40 \%$ solution in propylene glycol) treatment (groups III and IV, respectively) was initiated 2-3 wk after surgery and was continued for $3 \mathrm{wk}$. The vanadate concentration was adjusted every $3 \mathrm{~d}$ to maintain the plasma glucose level between 100 and $150 \mathrm{mg} / \mathrm{dl}$.

Immediately after surgery (i.e., pancreatectomy or sham pancreatectomy) rats were housed in individual cages and subjected to a 
standard light (6 a.m. to 6 p.m.)/dark (6 p.m. to 6 a.m.) cycle. Based on prior experience, rats received the identical daily allotment of Purina Rat Chow (Ralston-Purina Co., St. Louis, MO) in an amount $(0.1$ g/gram body weight per d) that sustained normal growth and was completely consumed by all of the animals.

After surgery, rats were weighed twice weekly and tail vein blood was collected for the determination of fed plasma glucose concentration at the same time ( 8 a.m.). A fasting plasma glucose concentration also was determined twice weekly on tail vein blood.

Euglycemic clamp study. Insulin-mediated whole body glucose uptake was measured in awake unstressed chronically catheterized rats using the euglycemic clamp in combination with $\left[{ }^{3} \mathrm{H}\right] 3$-glucose infusion, as previously described $(16,20)$. Briefly, 5 wk after pancreatectomy or sham-pancreatectomy rats were anesthetized with an intraperitoneal injection of phenobarbital $(50 \mathrm{mg} / \mathrm{kg}$ body wt) and indwelling catheters were inserted in the right internal jugular vein and in the left carotid artery. The venous catheter was extended to the level of the right atrium and the arterial catheter was advanced to the level of the aortic arch $(16,17) .1 \mathrm{wk}$ after catheter placement $(6 \mathrm{wk}$ after pancreatectomy or sham-operation) rats received an infusion of insulin at 12 $\mathrm{mU} / \mathrm{kg}$ min for $2 \mathrm{~h}$. A variable infusion of $25 \%$ glucose solution was started at time 0 and adjusted in order to clamp the plasma glucose concentration at $\sim 100 \mathrm{mg} / \mathrm{dl}$. A prime $(6 \mu \mathrm{Ci})$ continuous $(0.4 \mu \mathrm{Ci} /$ min) infusion of $\left[{ }^{3} \mathrm{H}\right] 3$-glucose (New England Nuclear, Boston, MA) was initiated at time zero and continued throughout the study $(16,20)$. Plasma samples for determination of $\left[{ }^{3} \mathrm{H}\right] 3$-glucose specific activity were obtained at 5-10-min intervals throughout the insulin clamp study. Plasma samples for determination of plasma insulin and plasma glucagon concentrations were obtained at time $-30,0,60,90$, and 120 min during the study. At the end of the 120-min study rats were injected with phenobarbital $(60 \mathrm{mg} / \mathrm{kg}$ body $\mathrm{wt})$, the abdomen was quickly opened, and the rectus abdominal and hindlimb muscle were freeze-clamped with aluminum tongs precooled in liquid nitrogen. All tissue samples were kept frozen at $-80^{\circ} \mathrm{C}$ for subsequent analysis. The absence of glycosuria was ascertained at the end of each euglycemic clamp study.

The study protocol was reviewed and approved by the Yale Animal Care and Use Committee.

Glycogen formation in vivo. Muscle glycogen synthesis was quantitated by two independent means: first, by determining the increment in cold glycogen concentration above fasting levels, and second, by measuring the incorporation of $\left[{ }^{3} \mathrm{H}\right] 3$-glucose counts into glycogen. Liver and muscle glycogen concentrations were determined after digestion with amyloglucosidase as previously described (21). The intraassay and the interassay coefficients of variation (CV) were $<10 \%$ (at $0.250 \mathrm{~g} \%$ tissue weight) when a liver or muscle homogenate was assayed as multiple aliquots. Aliquots of the tissue homogenate (200 $\mu$ l) were used to determine the amount of tritium label in glycogen. Glycogen was precipitated by washing in $10 \mathrm{vol}$ of absolute ethanol and by incubating for $1 \mathrm{~h}$ at $-20^{\circ} \mathrm{C}$. The procedure was repeated three times and then the precipitate was collected, dried down, and dissolved in water before scintillation counting. The recovery of free $\left[{ }^{3} \mathrm{H}\right] 3$-glucose, added to test the procedure, was $<1 \%$ of the free glucose radioactivity added to the homogenate in each assay. The glycogen synthetic rate was obtained by dividing the $\left[{ }^{3} \mathrm{H}\right] 3$-glucose radioactivity in glycogen (counts per minute per milligram tissue) by the mean specific activity of $\left[{ }^{3} \mathrm{H}\right] 3$-glucose in plasma during the insulin clamp (counts per minute per milligram plasma glucose). The rate of net glycogen synthesis is expressed as milligrams of glucose in glycogen per gram of tissue. During the initial $\mathbf{3 0}$ min after starting insulin, the plasma-tritiated glucose specific activity is not constant and blood was drawn every $5 \mathrm{~min}$ to define accurately the mean specific activity during this time period. This number was time-averaged with the mean tritiated glucose during the last $90 \mathrm{~min}$ of the insulin clamp to calculate the glycogen synthetic rate (Fig. 2).

Kinetic analysis of muscle glycogen synthase. The standard glycogen assay used is a modification $(22,23)$ of the method of Gilboe et al. (24) and Thomas et al. (25) and is based on the measurement of the incorporation of radioactivity into glycogen from UDP-U- $\left[{ }^{14} \mathrm{C}\right]$ glucose (UDPG). ${ }^{1}$ Synthase I, the active form, was measured at a final concentration of $0.11 \mathrm{mM}$ glucose-6-P, whereas synthase $D$, or total enzyme, was measured in the presence of $10 \mathrm{mM}$ glucose-6-P. The reaction mixtures originally contained $50 \mathrm{mM}$ Tris, $\mathrm{pH} 7.8,10 \%$ glycerol, 20 mM EDTA, $130 \mathrm{mM} \mathrm{KF}, 7 \mathrm{mg} / \mathrm{ml}$ oyster glycogen, and UDPG $(0.1-2$ $\mu \mathrm{Ci} / \mu \mathrm{mol})$. This was diluted with muscle homogenate to two-thirds of the original concentrations. Assays were conducted at final concentrations of $0.1,0.3,0.8,2.0,5.0$, and $10 \mathrm{mM}$ UDPG, the data were linearized as Eadie-Hofstee plots and fit using linear regression. The $K_{\mathrm{m}}$ for UDPG was taken to be the reciprocal of the slope, whereas $V \max$ was the $y$-intercept divided by the slope.

Analytical procedures. Plasma glucose was measured by the glucose oxidase method (glucose analyzer; Beckman Instruments, Palo Alto, CA) and plasma insulin by RIA using rat insulin standards. Plasma $\left[{ }^{3} \mathrm{H}\right] 3$-glucose radioactivity was measured in duplicate on the supernatants of barium hydroxide-zinc sulphate precipitates (Somogyi procedure) of plasma samples after evaporation to dryness to eliminate tritiated water.

Calculation. Data for total body glucose uptake and suppression of hepatic glucose production represent the mean values during the last $30 \mathrm{~min}$. The hepatic glucose production was calculated as the difference between the tracer-derived rate of appearance and the infusion rate of glucose. Total body glucose disposal was calculated by adding the rate of residual hepatic glucose production during the last $30 \mathrm{~min}$ of each insulin clamp to the glucose infusion rate during the same $30 \mathrm{~min}$ time period. The rate of net glycogen synthesis was calculated as number of $\left[{ }^{3} \mathrm{H}\right] 3$-glucose counts in glycogen per gram of muscle tissue divided by the time-weighed mean plasma $\left[{ }^{3} \mathrm{H}\right] 3$-glucose-specific activity (Fig. 2) (counts per minute per milligram glucose). For each rat, the mean of four determinations on rectus abdominal muscle and four on hindlimb muscle was used to approximate the mean whole body muscle glycogen concentration. All values are presented as the mean \pm SEM. Differences between groups were determined using oneway analysis of variance in conjunction with the Student NewmanKuels test.

\section{Results}

General characteristics of the animals (Table I and Fig. 1). There were no differences in the mean body weights among groups I-IV (Table I). Both the fasting $(P<0.05)$ and postmeal $(P<0.01)$ plasma glucose concentrations during the 2 -wk period before the insulin clamp study were significantly higher in the diabetic group (II) than in the other three groups (I, III, and IV) (Table I, Fig. 1). The fasting plasma insulin and glucagon concentrations were similar in all four groups, whereas the postmeal plasma insulin concentration was significantly and equally diminished in diabetics, vanadate-treated, and phlorizin-treated diabetic (groups II, III, and IV) compared with controls (group I) $(P<0.01)$.

Euglycemic hyperinsulinemic clamp (Figs. 2 and 3, Table II). Steady state plasma glucose and insulin concentrations during the hyperinsulinemic clamp were similar in all four groups (Table II). The CVs in plasma glucose and insulin levels were $<5$ and $10 \%$, respectively, in all four groups. In diabetic rats (group II), insulin-mediated glucose uptake was reduced by $28 \%(P<0.01)$ compared with controls (group I). Vanadate and phlorizin treatment of diabetic rats (group III and IV, respectively) completely restored tissue sensitivity to normal (Fig. 3).

Plasma glucagon concentration and residual hepatic glucose production during the insulin clamp study were not sig-

1. Abbreviations used in this paper: UDPG, UDP-(U $\left.\left[{ }^{14} \mathrm{C}\right]\right) \mathrm{glucose}$. 
Table I. General Characteristics of the Experimental Groups

\begin{tabular}{|c|c|c|c|c|c|c|c|}
\hline Group & $n$ & Body weight & $\begin{array}{c}\text { Fasting plasma } \\
\text { glucose }\end{array}$ & $\begin{array}{c}\text { Fed plasma } \\
\text { glucose }\end{array}$ & $\begin{array}{l}\text { Fasting plasma } \\
\text { insulin }\end{array}$ & $\begin{array}{l}\text { Fed plasma } \\
\text { insulin }\end{array}$ & $\begin{array}{l}\text { Fasting plasma } \\
\text { glucagon }\end{array}$ \\
\hline & & $g$ & \multicolumn{2}{|c|}{$m g / d l$} & \multicolumn{2}{|c|}{$n g / m l$} & $p g / m l$ \\
\hline I Controls & 9 & $306 \pm 7$ & $106 \pm 2$ & $146 \pm 1$ & $1.9 \pm 0.3$ & $5.1 \pm 0.3$ & $162 \pm 14$ \\
\hline II Diabetic & 9 & $302 \pm 15$ & $125 \pm 4^{*}$ & $336 \pm 32^{*}$ & $1.7 \pm 0.4$ & $2.4 \pm 0.6^{*}$ & $164 \pm 12$ \\
\hline III Diabetic plus vanadate & 9 & $298 \pm 12$ & $111 \pm 3$ & $142 \pm 3$ & $1.6 \pm 0.3$ & $2.5 \pm 0.4^{*}$ & $194 \pm 22$ \\
\hline IV Diabetic plus phlorizin & 7 & $289 \pm 12$ & $109 \pm 2$ & $144 \pm 3$ & $1.7 \pm 0.4$ & $2.3 \pm 0.5^{*}$ & $172 \pm 19$ \\
\hline
\end{tabular}

* $P<0.01$ compared with controls.

nificantly different in any of the four experimental groups (Table II).

Muscle glycogen synthesis (Fig. 4, A and B). The fasting muscle glycogen concentration was similar in groups I-IV and was $0.549 \pm 0.009(n=7)$ in group I, $0.533 \pm 0.010(n=8)$ in group II, $0.539 \pm 0.012(n=6)$ in group III, and $0.546 \pm 0.009$ $\mathrm{g} \%(n=6)$ in group IV.

The muscle glycogen concentration (Fig. $4 \mathrm{~A}$ ) at the end of the insulin clamp study was significantly reduced in diabetic rats (group II) compared with controls (group I) $(0.629 \pm 0.019$ vs. $0.898 \pm 0.025 \mathrm{~g} \% ; P<0.01)$, and restored to normal $(0.852 \pm 0.022 \mathrm{~g} \%)$ by vanadate (group III), but not by phlorizin $(0.679 \pm 0.016 \mathrm{~g} \% ; P<0.01)$ treatment (group IV). In response to insulin, muscle glycogen synthesis, estimated from the increment in cold glycogen concentration as well as from the tracer-derived glycogenic rate (Fig. $4 B$ ), was severely impaired in diabetic animals $(6.75 \pm 1.50$ and $7.78 \pm 1.56 \mu \mathrm{g} / \mathrm{g}$ tissue min, respectively) compared with controls $(28.29 \pm 1.81$ and $31.06 \pm 2.47 \mu \mathrm{g} / \mathrm{g}$ tissue min; $P<0.01)$. Vanadate treatment of diabetic rats completely normalized the muscle glycogenic rate $(25.54 \pm 1.82$ and $29.61 \pm 2.72 \mu \mathrm{g} / \mathrm{g}$ tissue $\mathrm{min})$. Phlorizin treatment of diabetic rats only slightly improved insulin-stimulated glycogen synthesis $(11.12 \pm 1.47$ and $12.94 \pm 1.28 \mu \mathrm{g} / \mathrm{g}$ tissue $\mathrm{min}$ ).

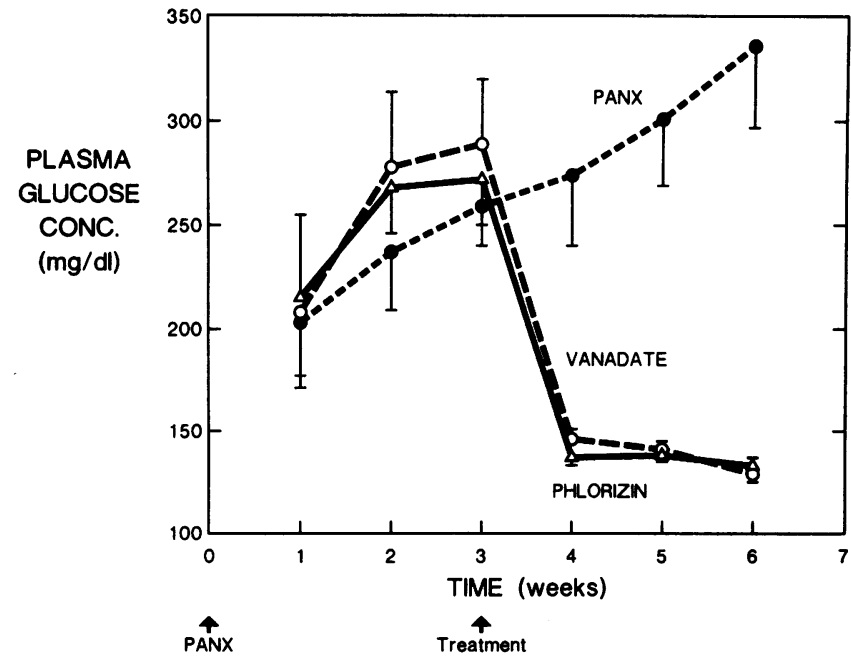

Figure 1. Effect of vanadate and phlorizin administration on postmeal plasma glucose concentrations of $90 \%$ partially pancreatectomized diabetic rats. $3 \mathrm{wk}$ after pancreatectomy rats were randomly divided in three groups: diabetic untreated (PANX; $\bullet$ ); diabetic treated with vanadate (VANADATE; $O$ ); and diabetic treated with phlorizin (PHLORIZIN; $\triangle$ ).
Liver glycogen concentrations (Fig. 5). The fasting and postinsulin liver glycogen concentrations were significantly higher in all diabetic groups (II, III, and IV) than in controls (I) (Fig. 5). However, after the insulin clamp study, no significant increment above basal could be detected in any of the experimental groups.

Muscle glycogen synthase (Fig. 6, $A$ and $B$ and Table III). The activity of glycogen synthase I (active) and D (total) were measured as a function of UDPG in muscle homogenates taken from rats in groups I-IV after the completion of the insulin clamp. The data for synthase I are presented as EadieHofstee plots in Fig. $6 \mathrm{~A}$ and for synthase D in Fig. $6 \mathrm{~B}$. The parameters $K_{\mathrm{m}}$ (UDPG) and $V_{\max }$ are estimated from the slope of each line and its $y$-intercept, and are reported in Table III. The $V_{\max }$ for both the I and D forms is depressed by pancreatectomy (group II) and is not affected by phlorizin treatment (group IV). Vanadate (group III) treatment, on the other hand, elevates the glycogen synthase $V_{\max }$ above that for normal rats (group I). The $K_{\mathrm{m}}$ (UDPG) is similar in all groups, and probably reflects synthase activation by insulin during the clamp.

\section{Discussion}

Insulin resistance is a prominent feature of diabetes mellitus in both man (26-29) and animals (16, 30-35). Glucose storage is a major determinant of insulin-mediated glucose disposal (36, 37) and muscle tissue is responsible for the majority of the glucose uptake under euglycemic hyperinsulinemic conditions $(38,39)$. Thus, it is important to define the role, if any, that the glycogenic pathway plays in the impaired insulin-mediated glucose uptake characteristic of the diabetic state.

In previous studies, we have demonstrated that phlorizin, an inhibitor of renal tubular glucose reabsorption, is capable of normalizing meal tolerance and insulin sensitivity in partially

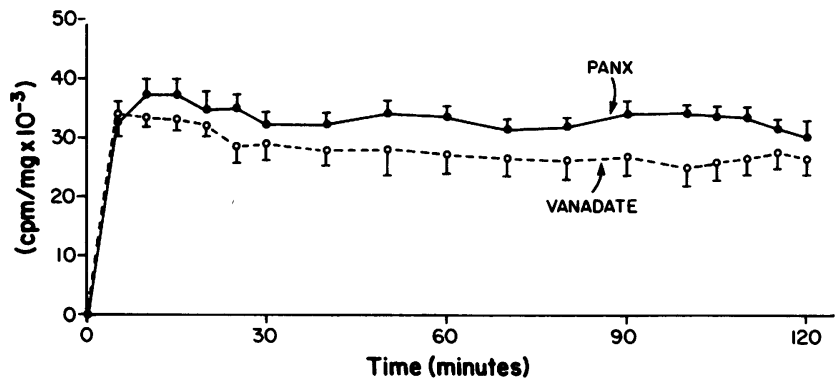

Figure 2. Plasma $\left[{ }^{3} \mathrm{H}\right]$ glucose specific activity time course during the euglycemic clamp study in diabetic untreated (PANX; $\bullet$ ); and diabetic vanadate-treated (VANADATE; 0 ) rats. 


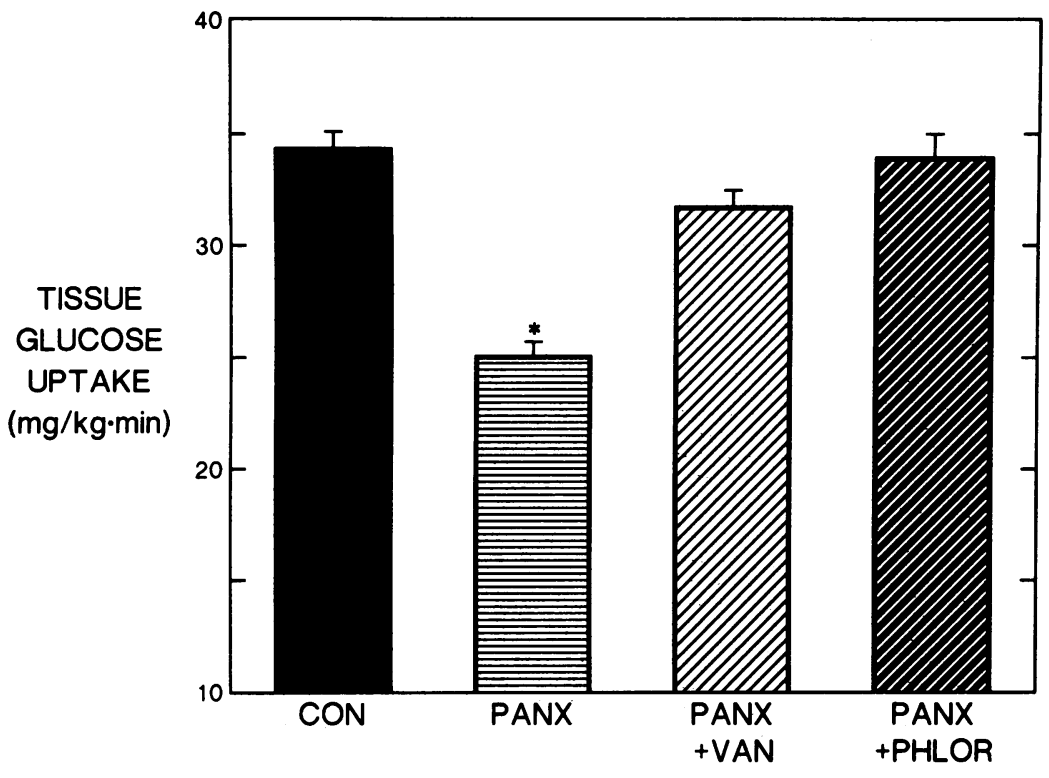

Figure 3. Insulin-mediated tissue glucose uptake during the euglycemic insulin clamp in controls $(\mathrm{CON}$; group I), diabetic (PANX; group II); diabetic treated with vanadate (PANX + VAN; group III) and diabetic treated with phlorizin (PANX + PHLOR; group IV). pancreatectomized diabetic rats. Because phlorizin corrects hyperglycemia, but is devoid of any known insulin-mimetic property, it is a perfect tool to distinguish the consequences of correction of hyperglycemia per se from other specific effects of a hypoglycemic agent.

Recently, Heyliger et al. (14) have extended previous observations regarding the insulin-like activity of vanadate in isolated cells (1-13) to the whole animal, and have demonstrated that this element is capable of normalizing elevated plasma glucose concentrations in diabetic rats.

This study was therefore undertaken to define the metabolic pathway(s) responsible for insulin resistance in an animal model of diabetes mellitus and to delineate the cellular mechanism(s) whereby vanadate normalizes glucose tolerance. Because an impairment in glycogen synthesis has been shown to be a major determinant of insulin resistance in non-insulindependent diabetes $(38,40-42)$, we have examined the effect of prolonged phlorizin and vanadate treatment on the kinetics of the rate-limiting enzyme of the glycogenic pathway, glycogen synthase.

After partial (90\%) pancreatectomy, rats develop a diabetic state characterized by mild fasting hyperglycemia and glucose intolerance (Table I, references 16 and 17). Fasting plasma insulin concentrations are normal, but the beta cell ability to respond to elevation in plasma glucose concentration is severely impaired $(16,17)$. As shown in Fig. 1, the treatment of diabetic rats with either vanadate or phlorizin completely normalized the meal tolerance without affecting the plasma insulin concentrations (Table I). However, whereas phlorizin decreases plasma glucose concentrations by inducing a state of persistent glycosuria (16), it has been suggested that vanadate mimics insulin action directly at the cellular level (15).

Tissue sensitivity to insulin, quantitated $6 \mathrm{wk}$ after pancreatectomy using the euglycemic clamp technique, was reduced by $28 \%(P<0.01)$ in the diabetic rats (group II) compared with controls (group I) (Fig. 3). This decrease is quite similar to that we previously reported in the same diabetic rat model at lower insulin concentrations (16). The correction of chronic hyperglycemia by either vanadate or phlorizin treatment completely normalized the whole body glucose uptake (Fig. 3). As shown in Table II, no differences among groups could be detected in hepatic glucose production and plasma glucagon concentrations during the insulin clamp study.

Altogether, these data demonstrate that both vanadate and phlorizin treatment can completely correct the defect in peripheral insulin-mediated glucose disposal that characterizes the partially pancreatectomized rat model. However the intracellular mechanism(s) whereby vanadate and phlorizin exert their beneficial effect on glucose disposal could not be determined.

Because incorporation of glucose into skeletal muscle glycogen is a major fate of an infused glucose load under eu-

Table II. Plasma Glucose, Insulin, and Glucagon Concentrations and Hepatic Glucose Production during the Euglycemic Clamp Studies

\begin{tabular}{|c|c|c|c|c|c|c|}
\hline Group & $n$ & Insulin infusion & $\begin{array}{c}\text { Steady-state } \\
\text { plasma insulin }\end{array}$ & $\begin{array}{l}\text { Steady-state } \\
\text { plasma glucose }\end{array}$ & $\begin{array}{l}\text { Steady-state } \\
\text { plasma glucagon }\end{array}$ & HGP \\
\hline & & mU/kg per min & $n g / m l$ & $m g / d l$ & $p g / m l$ & $\mathrm{mg} / \mathrm{kg}$ per min \\
\hline I Controls & 9 & 12 & $32 \pm 2$ & $102 \pm 1$ & $176 \pm 14$ & $0.31 \pm 0.11$ \\
\hline II Diabetic & 9 & 12 & $34 \pm 3$ & $105 \pm 1$ & $178 \pm 15$ & $0.52 \pm 0.17$ \\
\hline III Diabetic plus vanadate & 9 & 12 & $30 \pm 2$ & $103 \pm 1$ & $177 \pm 12$ & $0.24 \pm 0.07$ \\
\hline IV Diabetic plus phlorizin & 7 & 12 & $29 \pm 4$ & $101 \pm 2$ & $180 \pm 16$ & $0.35 \pm 0.11$ \\
\hline
\end{tabular}

HGP, hepatic glucose production. 

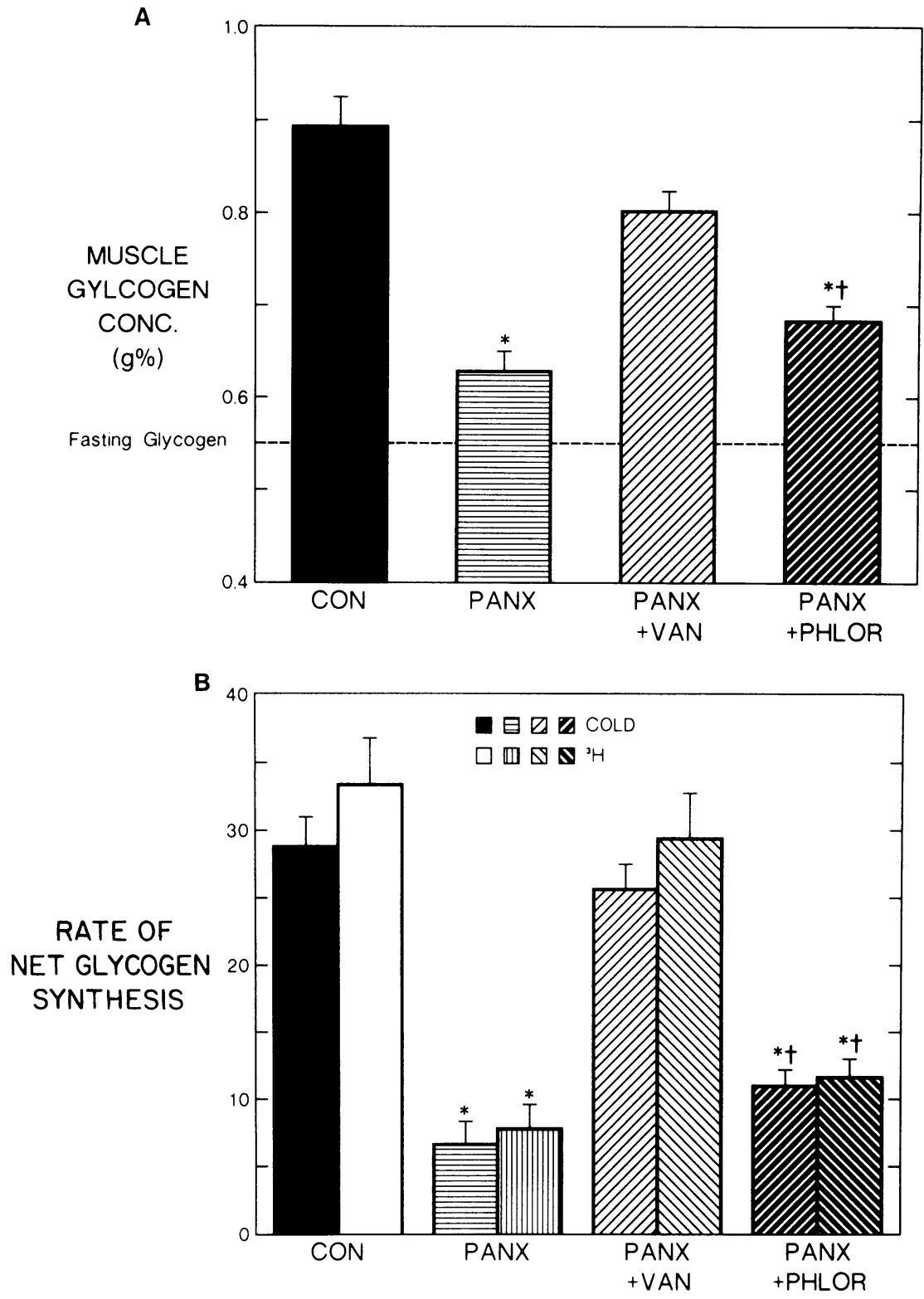

Figure 4. (A) Skeletal muscle glycogen concentration at the end of the euglycemic insulin clamp in controls (CON; group I); diabetic (PANX; group II); diabetic treated with vanadate (PANX + VAN; group III); and diabetic treated with phlorizin (PANX + PHLOR; group IV). (B) Rates of skeletal muscle net glycogen synthesis during the euglycemic clamp in controls (CON: group I); diabetic (PANX; group II); diabetic treated with vanadate (PANX + VAN; group III); and diabetic treated with phlorizin (PANX + PHLOR; group IV). Muscle glycogen synthesis was quantitated by determining the increment in 'cold' glycogen concentration above fasting levels (COLD) and by measuring the incorporation of $\left[{ }^{3} \mathrm{H}\right]$ glucose counts into glycogen $\left[{ }^{3} \mathrm{H}\right]$.

glycemic hyperinsulinemic conditions, we examined the influence of phlorizin and vanadate treatment on the glycogenic pathway.

The muscle glycogen concentration (Fig. $4 A$ ) at the end of the insulin clamp were severely reduced in diabetic rats compared with controls $(P<0.01)$. The correction of hyperglycemia with vanadate restored muscle glycogen levels to normal, whereas phlorizin treatment was unable to normalize the muscle glycogen concentrations. The difference between vanadate- and phlorizin-treated animals is particularly interesting because the whole body glucose disposal was similar in these two groups.

To quantitate the skeletal muscle glycogenic rates, we infused tritiated glucose during the euglycemic clamp and measured the time-course plasma glucose-specific activity as well as the incorporation of ${ }^{3} \mathrm{H}$ counts into muscle glycogen at the end of the study. Moreover, because the muscle glycogen concentration after $24 \mathrm{~h}$ of fasting was similar in all rats, it was possible to calculate the muscle glycogen synthetic rates from the cold glycogen concentrations as well. The results from these two independent measurements of glucose incorporation into glycogen (Fig. $4 \mathrm{~B}$ ) again confirmed that the insulin-stimulated glycogen repletion was severely impaired in diabetic rats and was completely restored to normal by the treatment with vanadate, but not with phlorizin.

Because muscle mass in the rat represents $\sim 40 \%$ of the body weight $(43,45)$, it is possible to calculate the contribution of skeletal muscle glycogen synthesis to the whole body glucose uptake. In normal rats (group I), $35 \%$ of the tissue glucose uptake (Fig. 7) can be accounted for by muscle glycogen repletion, while in diabetic rats only $10-15 \%$ of the rate of disappearance $\left(R_{\mathrm{d}}\right)$ was accounted for by muscle glycogen deposition. The difference in glucose incorporation into glycogen $(8.62 \mathrm{mg} / \mathrm{kg}$ per $\mathrm{min})$ between control and diabetic rats can account for $90 \%$ of the impairment in whole body glucose uptake (Fig. 7) under the conditions of this study. This result 


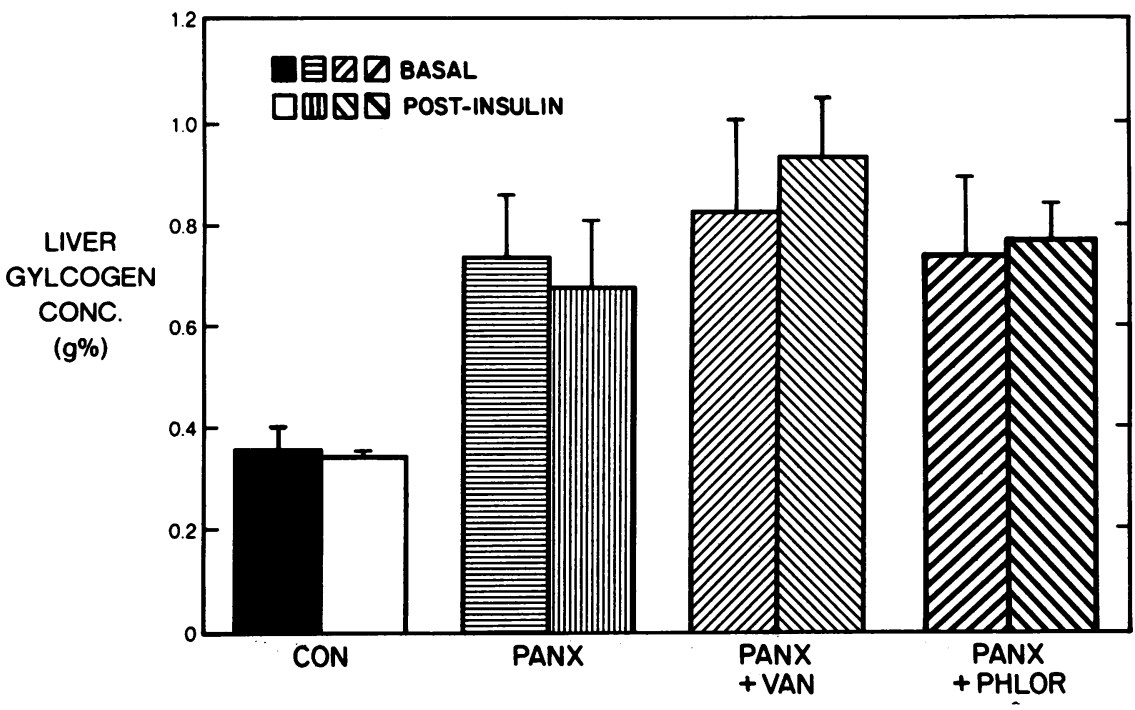

Figure 5. Liver glycogen concentration in the fasting state (left column) and at the end of the euglycemic clamp (right column) in controls (CON; group I); diabetic (PANX; group II); diabetic treated with vanadate (PANX + VAN; group III); and diabetic treated with phlorizin (PANX + PHLOR; group IV). suggests that the impairment in the glycogenic pathway in skeletal muscle is indeed the major intracellular defect in the partially pancreatectomized diabetic rat. However, because we did not measure the oxidative and nonoxidative glycolytic fluxes these data cannot definitely exclude the presence of additional intracellular defects in the oxidative pathway. Moreover, it has to be emphasized that the rate-limiting step for insulin-mediated glucose disposal can vary in the function of the plasma insulin concentrations (46).
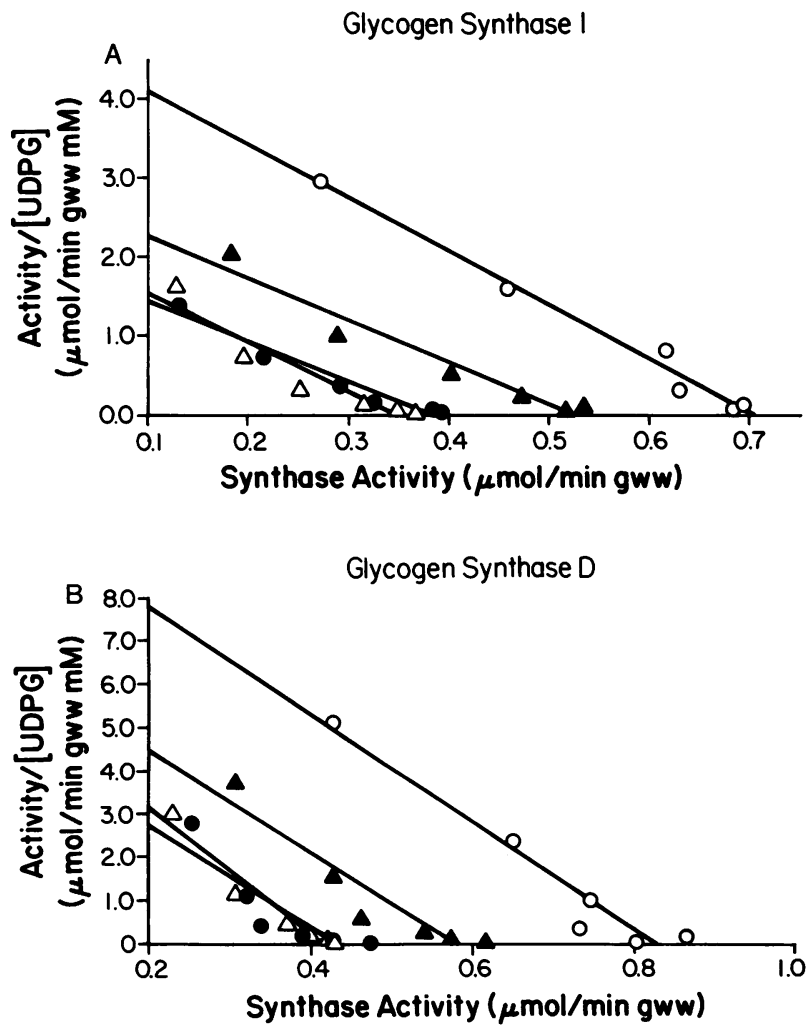

Figure 6. Kinetic analysis of the muscle glycogen synthase (EadieHofstee plots) in Controls ( $\Delta)$; diabetic (๑); diabetic treated with vanadate (o); and diabetic treated with phlorizin $(\Delta)$.
After vanadate therapy, muscle glycogen formation represented $32 \%$ of the $R_{\mathrm{d}}$ similarly to what observed in control rats (Fig. 7), whereas after phlorizin, only $13 \%$ of the glucose uptake could be accounted for by muscle glycogen synthesis. Because the meal tolerance as well as the insulin-mediated glucose disposal were equally normalized by either vanadate or phlorizin treatment, but the improvement in muscle glycogen repletion was observed only after vanadate, this latter effect has to be considered specific of the element and independent from the correction of the hyperglycemic state.

Additionally, this finding also seems to validate previous observations (47) that the plasma glucose concentration influences insulin sensitivity primarily by up- and downregulating the glucose transport system. In fact, whereas $100 \%$ of the improvement in insulin-mediated glucose disposal was due to the enhanced muscle glycogen deposition in the vanadatetreated animals, only $22 \%$ of the increase in glucose uptake was represented by augmented glucose storage in skeletal muscle after phlorizin therapy, suggesting that phlorizin corrects the defect in glucose transport, but not the intracellular defect in glycogen synthesis.

To determine if the observed effects of vanadate treatment were mediated by allosteric changes in the rate-limiting en-

Table III. Skeletal Muscle Glycogen Synthase $K_{m}$ and $V_{\max }$ at the End of the Euglycemic Clamp Studies

\begin{tabular}{llccc}
\hline \multicolumn{1}{c}{ Group } & $n$ & $K_{\mathrm{m}}$ & $V_{\max }$ & $r^{*}$ \\
\hline & & $m M$ & $\mu$ mol/g wet wt & \\
I Controls & I 5 & $0.187 \pm 0.032$ & $0.524 \pm 0.049$ & 0.9739 \\
& D & $0.084 \pm 0.023$ & $0.577 \pm 0.059$ & 0.9398 \\
II Diabetic & I 5 & $0.196 \pm 0.063$ & $0.382 \pm 0.030$ & 0.9758 \\
& D & $0.085 \pm 0.039$ & $0.434 \pm 0.044$ & 0.8740 \\
III Diabetic plus & I 5 & $0.147 \pm 0.030$ & $0.705 \pm 0.089$ & 0.9917 \\
vanadate & D & $0.081 \pm 0.003$ & $0.828 \pm 0.117$ & 0.9685 \\
IV Diabetic plus & I 5 & $0.160 \pm 0.010$ & $0.349 \pm 0.015$ & 0.9413 \\
phlorizin & D & $0.069 \pm 0.007$ & $0.419 \pm 0.014$ & 0.9725
\end{tabular}

* $r$ value is from linear regression of the Eadie-Hofstee plots shown in Fig. 6. All other values are also derived from those plots. 


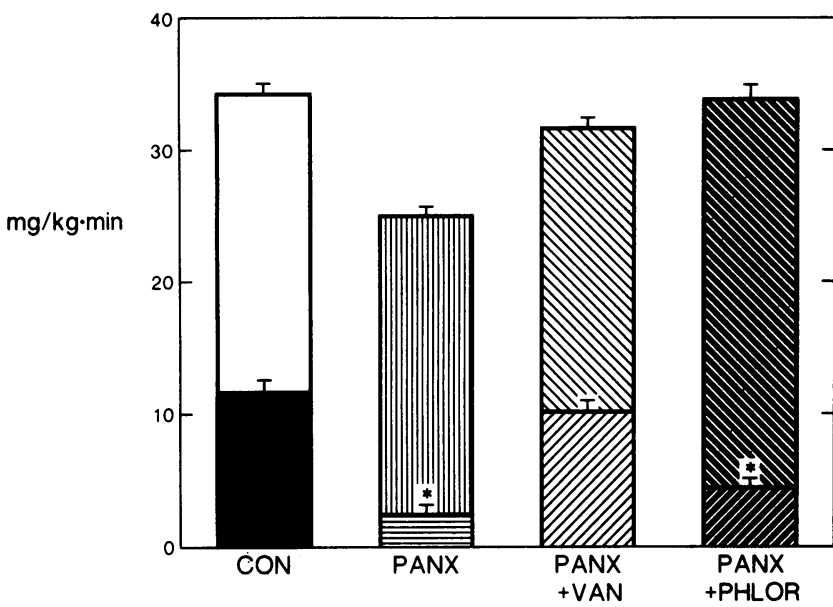

Figure 7. Contribution of the muscle glycogen synthesis to the whole body tissue glucose uptake during the euglycemic clamp in controls (CON; group I); diabetic (PANX; group II); diabetic treated with vanadate (PANX + VAN; group III); and diabetic treated with phlorizin (PANX + PHLOR; group IV). The whole body muscle glycogenic rates displayed in this figure are obtained from the data shown in Fig. $4 B$ assuming that total body muscle mass in the rat is $40 \%$ of the body weight (43-45).

zyme of the glycogenic pathway, we performed a kinetic analysis of the rectus muscle glycogen synthase. The enzyme assay was conducted in homogenate of tissue obtained at the end of the insulin clamp study. Therefore, it reflects the status of the enzyme after prolonged in vivo insulinization. The $V_{\max }$, I and $\mathrm{D}$, were significantly reduced in diabetic rats compared with controls $(P<0.05)$. Vanadate-treated diabetic rats displayed a $V_{\max }$ increased beyond the control level, whereas the phlorizin-treated group had $V_{\max }$ similar to that of untreated diabetic rats (Fig. 6 and Table III). These results demonstrate that a significant reduction in glycogen synthase $V_{\max }$ persisted after $2 \mathrm{~h}$ of in vivo insulinization in skeletal muscle of diabetic rats. More importantly, perhaps, vanadate therapy increased the $V_{\max }$ of the skeletal muscle glycogen synthase to supranormal levels. This effect cannot be ascribed to the correction of the hyperglycemia per se because phlorizin treatment had no direct influence on the kinetics of the enzyme. The potentiation of insulin action on skeletal muscle glycogen synthase after in vivo vanadate administration is consistent with recent observations in isolated adipocytes $(3,4)$. The similar kinetics of the glycogen synthase in untreated and phlorizin-treated diabetic rats seem to suggest that the rate of glucose disposal does not influence the enzyme activity under these in vivo conditions, because phlorizin normalizes tissue glucose uptake but does not improve glycogen synthase activity.

In conclusion, these results demonstrate that an impairment in skeletal muscle glycogen synthesis is a major determinant of insulin resistance in $90 \%$ partially pancreatectomized rats, and vanadate, but not phlorizin, selectively reverses the defect in the glycogenic pathway by stimulating the $V_{\max }$ of the enzyme glycogen synthase.

\section{Acknowledgments}

The authors would like to thank Eveline Klein-Robbenhaar for her excellent technical assistance and Debbie Yung for her expert secre- tarial assistance. The authors are also grateful to Dr. Ralph De Fronzo and Dr. Gerald Shulman for their helpful comments.

This work was supported in part by a grant (to L. Rossetti) from the Juvenile Diabetes Foundation (188016).

\section{References}

1. Dubyak, G. R., and A. Kleinzeller. 1980. The insulinomimetic effect of vanadate in isolated rat adipocytes. J. Biol. Chem. 255:53065312.

2. Schechter, Y., and S. J. D. Karlish. 1980. Insulin-like stimulation of glucose oxidation in rat adipocytes by vanadyl ions. Nature (Lond.). 284:556-558.

3. Tamura, S., T. A. Brown, R. E. Dubler, and J. Larner. 1983. Insulin like effect of vanadate on adipocyte glycogen synthase and on phosphorylation of 95,000 dalton subunit of the insulin receptor. Biochem. Biophys. Res. Commun. 113:80-86.

4. Tamura, S., T. A. Brown, J. H. Whipple, Y. Fujita-Yamaguchi, R. E. Dubler, K. Cheng, and J. Larner. 1984. A novel mechanism for the insulin-like effect of vanadate on glycogen synthase in rat adypocytes. J. Biol. Chem. 259:6650-6658.

5. Green, A. 1986. The insulin-like effect of sodium vanadate on adipocyte glucose transport is mediated at a post-insulin receptor level. Biochem. J. 238:663-669.

6. Duckworth, W. C., S. S. Solomon, J. Lieonieks, F. G. Hamel, S. Hand, and D. E. Peavy. 1988. Insulin-like effects of vanadate in isolated rat adipocytes. Endocrinology. 122:2285-2289.

7. Clark, A. S., J. M. Fagan, and W. E. Mitch. 1985. Selectivity of the insulin like actions of vanadate on glucose and protein metabolism in skeletal muscle. Biochem. J. 232:273-276.

8. Challis, R. A. J., B. Leighton, F. J. Lozeman, L. Budohoski, and E. A. Newsholme. 1987. Effect of chronic administration of vanadate to the rat on the sensitivity of glycolysis and glycogen synthesis in skeletal muscle to insulin. Biochem. Pharmacol. 36:357-361.

9. Gil, J., M. Miralpeix, J. Carreras, and R. Bartrons. 1988. Insulin-like effects of vanadate on glucokinase activity and fructose 2,6-biphosphate levels in the liver of diabetic rats. J. Biol. Chem. 263:18671871.

10. Tolman, E. L., E. Barris, M. Burns, A. Pansini, and R. Partridge. 1979. Effects of vanadium on glucose metabolism in vitro. Life Sci. 25:1159-1164.

11. Bosch, F., J. Arino, A. Gomez-Foix, and J. J. Guinovart. 1987. Glycogenolytic, noninsulin-like effects of vanadate on rat hepatocyte glycogen synthase and phosphorylase. J. Biol. Chem. 262:218-222.

12. Bingham Smith, J. 1983. Vanadium ions stimulate DNA synthesis in swiss mouse 3T3 cells. Proc. Natl. Acad. Sci. USA. 80:61626166.

13. Earp, H. S., R. A. Rubin, K. S. Austin, and R. C. Dy. 1983. Vanadate stimulates tyrosine phosphorylation of two proteins in raji human lymphoblastoid cell membranes. FEBS (Fed. Eur. Biochem. Soc.) Lett. 161:180-184.

14. Heyliger, C. E., A. G. Tahiliani, and H. J. McNeill. 1985. Effect of vanadate on elevated blood glucose and depressed cardiac performance of diabetic rats. Science (Wash. DC). 227:1474-1477.

15. Meyerovitch, J., Z. Farfel, J. Sack, and Y. Schechter. 1987. Oral administration of vanadate normalizes blood glucose levels in streptozocin-treated rats. Characterization and mode of action. J. Biol. Chem. 262:6658-6664.

16. Rossetti, L., D. Smith, G. I. Shulman, D. Papachristou, and R. A. DeFronzo. 1987. Correction of hyperglycemia with phlorizin normalizes tissue sensitivity to insulin in diabetic rats. J. Clin. Invest. 79:1510-1515.

17. Rossetti, L., G. I. Shulman, W. Zawalich, and R. A. DeFronzo. 1987. Effect of chronic hyperglycemia on in vivo insulin secretion in partially pancreatectomized rats. J. Clin. Invest. 80:1037-1044.

18. Foglia, V. G. 1944. Caracteristicas de la diabetes en la rata. Rev. Soc. Argent. Biol. 20:21-37. 
19. Bonner-Weir, S., D. F. Trent, and G. C. Weir. 1983. Partial pancreatectomy in the rat and subsequent defect in glucose-induced insulin release. J. Clin. Invest. 71:1544-1553.

20. Smith, D., L. Rossetti, E. Ferrannini, C. M. Johnson, C. Cobelli, G. Toffolo, L. D. Katz, and R. A. DeFronzo. 1987. In vivo glucose metabolism in the awake rat: tracer and insulin clamp studies. Metab. Clin. Exp. 36:1176-1186.

21. Shulman, G. I., L. Rossetti, D. Rothman, J. Blair, and D. Smith. 1987. Quantitative analysis of glycogen repletion by nuclear magnetic resonance spectroscopy in the conscious rat. J. Clin. Invest. 80:387-393.

22. Laughlin, M. R., W. A. Petit, J. M. Dizon, R. G. Shulman, and E. J. Barrett. 1988. NMR measurements of in vivo myocardial glycogen metabolism. J. Biol. Chem. 263:2285-2291.

23. Shulman, G. I., D. L. Rothman, Y. Chung, L. Rossetti, W. A. Petit, E. J. Barrett, and R. G. Shulman. $1988 .{ }^{13} \mathrm{C}$ NMR studies of glycogen turnover in the perfused rat liver. J. Biol. Chem. 263:50275029.

24. Gilboe, D. P., K. L. Larson, and F. Q. Nuttal. 1972. Radioactive method for the assay of glycogen phosphorylases. Anal. Biochem. 47:20-27.

25. Thomas, J. A., K. K. Schlender, and J. Larner. 1968. A rapid filter paper assay for UDP-glucose-glycogen glucosyltransferase, including an improved biosynthesis for UDP (14C) glucose. Anal. Biochem. 25:486-499.

26. DeFronzo, R. A., R. Hendler, and D. Simonson. 1982. Insulin resistance is a prominent feature of insulin-dependent diabetes. Diabetes. 31:795-801.

27. DeFronzo, R. A., R. Gunnarsson, O. Bjorkman, and J. Wahren. 1985. Effect of insulin on peripheral and splanchnic glucose metabolism in noninsulin-dependent (Type II) diabetes mellitus. $J$. Clin. Invest. 76:149-155.

28. Kolterman, O. G., R. S. Gray, J. Griffin, P. Burstein, J. Insel, J. A. Scarlett, and J. M. Olefsky. 1981. Receptor and postreceptor defects contribute to the insulin resistance in non-insulin dependent diabetes mellitus. J. Clin. Invest. 68:957-969.

29. Hollenbeck, C. B., Y. D. I. Chen, and G. M. Reaven. 1984. A comparison of the relative effects of obesity and non-insulin-dependent diabetes mellitus on in vivo insulin-stimulated glucose utilization. Diabetes. 33:622-626.

30. Reaven, G. M., W. S. Sageman, and R. S. Swenson. 1977. Development of insulin resistance in normal dogs following alloxaninduced insulin deficiency. Diabetologia. 13:459-462.

31. Pupo, A. A., M. J. M. Ursich, E. Iamaguchi, and F. G. Vasconcellos. 1976. Acute and late phase insulin secretion and glucose tolerance in mild alloxan diabetes in dog. Diabetes. 25:161-166.

32. Bevilacqua, S., E. J. Barret, D. Smith, D. C. Simonson, P. Bratusch-Marrain, E. Ferrannini, and R. A. DeFronzo. 1985. Hepatic and peripheral insulin resistance following streptozocin-induced insulin deficiency in the dog. Metab. Clin. Exp. 34:817-825.
33. Levy, J., J. R. Gavin, III, A. Fausto, R. L. Gingerich, and L. V. Avioli. 1984. Impaired insulin action in rats with non-insulin dependent diabetes. Diabetes. 33:901-906.

34. Dall'Aglio, E., H. Chang, C. B. Hollenbeck, C. E. Mondon, C. Sims, and G. M. Reaven. 1985. In vivo and in vitro resistance to maximal insulin stimulated glucose disposal in insulin deficiency. Am. J. Physiol. 249:E312-E316.

35. Le Marchand-Brustel, Y., and P. Freychet. 1979. Effect of fasting and streptozocin diabetes on insulin binding and action in the isolated mouse soleus muscle. J. Clin. Invest. 64:1505-1515.

36. Lillioja, S., D. M. Mott, J. K. Zawadzki, A. A. Young, W. G. Abbott, and C. Bogardus. 1986. Glucose storage is a major determinant of in vivo "insulin resistance" in subjects with normal glucose tolerance. J. Clin. Endocrinol. \& Metab. 62:922-927.

37. DeFronzo, R. A., E. Jacot, E. Jequier, E. Maeder, J. Wahren, and J. P. Felber. 1981. The effect of insulin on the disposal of intravenous glucose: results from indirect calorimetry and hepatic and femoral venous catheterization. Diabetes. 30:100-107.

38. Young, A. A., C. Bogardus, Wolfe-Lopez, and D. M. Mott. 1988. Muscle glycogen synthesis disposition of infused glucose in humans with reduced rates of insulin-mediated carbohydrate storage. Diabetes. 37:303-308.

39. Katz, L. D., M. G. Glickman, S. Rapoport, E. Ferrannini, and R. A. DeFronzo. 1983. Splanchnic and peripheral disposal of oral glucose in man. Diabetes. 32:675-679.

40. Mandarino, L., Z. Mader, O. G. Kolterman, J. M. Bell, and J. M. Olefsky. 1986. Adipocyte glycogen synthase and pyruvate dehydrogenase in obese and type II diabetic subjects. Am. J. Physiol. 251:E489-E496.

41. Bogardus, C., L. Lillioja, K. Stone, and D. Mott. 1984. Correlation between muscle glycogen synthase activity and in vivo insulin action in man. J. Clin. Invest. 73:1186-1190.

42. Kruszynksa, Y. T., G. Petranyi, P. D. Home, R. Taylor, and K. G. M. M. Alberti. 1986. Muscle enzyme activity and insulin sensitivity in type I (insulin-dependent) diabetes mellitus. Diabetologia. 29:669-705.

43. Pitts, G. C. 1984 . Body composition in the rat: interactions of exercise, age, sex and diet. Am. J. Physiol. 246:R495-R501.

44. Tepper, B. J., and R. B. Kanarek. 1985. Dietary self-selection patterns of rats with mild diabetes. J. Nutr. 115:699-709.

45. Curtis-Prior, P. B., J. Trethewey, G. W. Stewart, and T. Hanley. 1969. The contribution of different organs and tissues of the rat and to assimilation of glucose. Diabetologia. 5:384-391.

46. Kubo, K., and J. E. Foley. 1986. Rate-limiting steps for insulin-mediated glucose uptake into perfused rat hindlimb. Am. J. Physiol. 250:E100-E102.

47. Kahn, B. B., S. W. Cushman, G. I. Shulman, R. A. DeFronzo, and L. Rossetti. 1987. Reversal of insulin-resistant glucose-transport in adipose cells from diabetic rats by normalization of plasma glucose without insulin therapy. Clin. Res. 35:507a. (Abstr.) 